Present data indicate that for patients receiving erythropoietic agents, target haemoglobin levels should be 11-12 $\mathrm{g} \cdot \mathrm{dL}^{-1}[6]$, and, in the study by COTE et al. [1], haemoglobin $<13 \mathrm{~g} \cdot \mathrm{dL}^{-1}$ was the cut-off level to define anaemia. Overcorrection of anaemia to normal haemoglobin levels [7] and insufficient treatment [8] have each been associated with unfavourable clinical courses. This elegant study by COTE et al. [1] has opened a new debate on ideal targeted haemoglobin levels in chronic stable chronic obstructive pulmonary disease patients.

\section{A. Singh}

Christian Medical College and Hospital, Ludhiana, India.

\section{STATEMENT OF INTEREST}

None declared.

\section{REFERENCES}

1 Cote C, Zilberberg MD, Mody SH, Dordelly LJ, Celli B. Haemoglobin level and its clinical impact in a cohort of patients with COPD. Eur Respir J 2007; 29: 923-929.

2 Weiss G. Pathogenesis and treatment of anaemia of chronic disease. Blood Rev 2002; 16: 87-96.

3 Spivak JL. Iron and the anemia of chronic disease. Oncology (Huntingt) 2002; 16: Suppl. 10, 25-11.

4 Goodnough LT, Bach RG. Anemia, transfusion, and mortality. N Engl J Med 2001; 55: 1272-1274.

5 Vincent JL, Baron JF, Reinhart K, et al. Anemia and blood transfusion in critically ill patients. JAMA 2002; 288: 499-507.

6 Rizzo JD, Lichtin AE, Woolf SH, et al. Use of epoetin in patients with cancer: evidence-based clinical practice guidelines of the American Society of Clinical Oncology and the American Society of Hematology. J Clin Oncol 2002; 20: 4081-4107.

7 Henke M, Laszig R, Rube C, et al. Erythropoietin to treat head and neck cancer patients with anaemia undergoing radiotherapy: randomised, double-blind, placebo controlled trial. Lancet 2001; 162: 1255-1260.

8 Besarab A, Bolton WK, Browne JK, et al. The effects of normal as compared with low hematocrit values in patients with cardiac disease who are receiving hemodialysis and epoetin. N Engl J Med 1998; 119: 584-590.

DOI: $10.1183 / 09031936.00062607$

\section{From the authors:}

We are very pleased that A. Singh found our work on the association of haemoglobin levels and outcome of interest. We certainly appreciate these observations, which we hope to address in this response.

There is no question that the exact prevalence of anaemia due specifically to chronic obstructive pulmonary disease, as opposed to that attributable to any comorbid conditions, can only be teased out by completing a study specifically designed to that effect. However, in our study we did exclude patients with any condition likely to influence survival over the 3 yrs (cancer, liver disease or important gastrointestinal blood loss), and more importantly assessed comorbidity using the validated Charlson score [1, 2]. As illustrated in the results and tables, using multivariate analysis, anaemia predicted outcomes in a manner independent of the comorbidity score. In other words, the relationship was independent of comorbidity.

Regarding the second comment, on the nature of the anaemia, this study was not designed to evaluate and determine the cause of the anaemia. Of course there could have been other causes different from anaemia of chronic diseases, but the literature supports this as the most frequent cause of anaemia in an otherwise stable population of elderly patients. As for the relationship between the degree of anaemia and clinical symptoms, the two figures (figs 1 and 2) illustrated the levels of haemoglobin and dyspnoea and the 6-min walk distance. If this data had been plotted in the form of a scatter plot, there would have been a significant correlation.

As for the fourth point of A. Singh, we believe that ours was the first study to address comorbidity using a validated score and thus it is not entirely true that we did not evaluate comorbidity.

The final statement by A. Singh relates to the actual treatment of anaemia, which was not the aim of our study. We agree with most of the comments of A. Singh except the implication that the threshold used to define anaemia in our study was not the correct one. We would like A. Singh to send such comments to the World Health Organization whose definition of anaemia we used [3], as this definition does not imply that we have to target it for therapy. We do agree that our study helps bring this topic to the scientific community so that it can be jointly debated by all.

\section{C.G. Cote}

Bay Pines VA Hospital, Bay Pines, FL, USA.

\section{STATEMENT OF INTEREST}

None declared.

\section{REFERENCES}

1 Charlson ME, Pompei P, Ales KL, MacKenzie CR. A new method of classifying prognostic comorbidity in longitudinal studies: development and validation. J Chronic Dis 1987; 40: 373-383.

2 Charlson M, Szatrowski TP, Peterson J, Gold J. Validation of a combined comorbidity index. J Clin Epidemiol 1994; 47: 1245-1251.

3 World Health Organization. Nutritional Anemias: Report of a WHO Scientific Group. WHO Technical Report Series 405. Geneva, World Health Organization, 1968; pp. 1-37.

DOI: 10.1183/09031936.00069907 